\title{
Timelines in Spectral Composition: A Cognitive Approach to Musical Creativity
}

\author{
José L. Besada \& Cristóbal Pagán Cánovas \\ [Preprint version: no figures embedded]
}

\begin{abstract}
What takes place in the minds of composers when they struggle to incorporate a given temporal concept to a musical work? Spectral composers have produced detailed theoretical proposals about time in music, but how exactly those ideas influenced their musical practices remains an extremely challenging question. Graphical representations in their sketches provide invaluable clues. Through the analyses of Gérard Grisey's and Kaija Saariaho's manuscripts, we show how the theoretical frameworks for the basic cognitive operations of blending and anchoring, which underlie the construction of complex meanings, can shed light on the intricate musical uses of timelines by spectral composers. We combine the universal claims of this cognitive analysis with the diachronic perspective of a musicological study, teasing out the mental paths that these composers may have followed to create novel aesthetic proposals from their experience with graphic representations of sound, mainly spectrograms, and from techniques of electroacoustic studios. Thus we pave the way towards a common language for understanding time representation across electroacoustics and music in general, based on this mixed methodology. Through such shared tenets, the cognitive study of music can reciprocally contribute to burgeoning fields such as time representation, meaning construction, and creativity.
\end{abstract}

\section{INTRODUCTION}

Time is a primary issue for composers of any period, although this is not always evident from the documents they leave behind. This is not the case, however, for spectral composers, who have often addressed the topic explicitly in their writings. Grisey, one of the key figures of spectral music, stated in a posthumous text that 'spectral music has temporal origins' (Grisey 2000: 1) and his most profound theoretical essay focused on time (Grisey 1987). Other authors beyond the French core have endorsed this attitude, considering for instance that, above all, a musician 'builds and regulates the experience of the speed of time passing' (Saariaho 2000: 111).

Throughout our paper, we will be focusing on Gérard Grisey's and Kaija Saariaho's theoretical and musical production, which also incorporates reception, in a feedback loop. Our goal is to understand the way in which time representations have shaped their compositional practices. Their conceptualisation of time has already been approached by several scholars via phenomenology: Grisey's thoughts have been often compared with Bergson's (Orcalli 1991; Manfrin and Piras 2003; Dufourt 2004; Pasler 2004; Exarchos 2018); we have also found an essay on Saariaho through Bachelard's philosophy (Sijouva-Gunaratman 2003). Despite the validity of these scholarly exegeses, we regard them as speculative to some extent: for instance, Grisey never made an explicit mention of Bergson in his writings.

Our methodological position will take another path. Informed by cognitive science, our analyses will target the mental operations underlying temporal concepts in the creative practices of spectral composers. We seek to explain those exceptional cases of creativity through what we are coming to know about the general functioning of imagination and 
reasoning, moving forward in the direction of research already published in this journal (Kendall 2010). In addition, we follow the footsteps of recent studies about cognitive anchoring within musical practices (Besada 2019a; 2019b; Zbikowski 2019).

Seeking tangible data for this difficult task, we turn to the visual representations used by composers during their creative practices. The use of this corpus of visualizations is congenial with current trends in sketch studies (Hall and Sallis 2004). For access to relevant materials, we have visited the Paul Sacher Stiftung, which hosts Grisey's and Saariaho's collections of manuscripts. Focusing on specific spatial features rather than on comprehensive reconstructions of compositional strategies, we seek to show the cognitive processes at work in their creative use of perceptual representations of time.

\section{VISUALISING TIME}

\subsection{Blending and anchoring}

For our purposes, we first need some understanding about human symbolic skills. The ability of our species to produce and handle symbols has been key in our cultural-perhaps also in our biological-evolution (Deacon 1998). Symbols allow us to build sophisticated structures of knowledge from comparatively simple formal cues. Language, whether in aural, visual, or tactile form, is the archetype. Nevertheless, language is just one among the many manifestations of the human capacity to build conceptual significance out of perceptual patterns for communication, thought, and action. Consider multimodal faceto-face interaction: beyond language, it also involves gesture, gaze, prosody, rhythm, body posture, non-vocal sounds, and so forth. However, flagging symbolic abilities as the key to what makes us human has a great danger of oversimplification. Humans are the species that produces language and music, indeed, but also the species that has consciousness and politics, or builds skyscrapers and spaceships. None of these manifestations of the human mind could stand on its own as a species-defining feature. Instead, they all must be products of one or more basic cognitive capacities.

Among the several cognitive operations that could explain these manifestations and be ultimately responsible for the human spark, one stands out in cognitive science over the past few decades: the uniquely-human ability to recombine disparate experiences and knowledge structures into novel, purposeful mental wholes. Prominent theoretical frameworks that have sought to model this capacity for integrated and networked thought are conceptual integration or blending (Fauconnier and Turner 2002), bisociation (Koestler 1964), cognitive fluidity (Mithen 1999), or combinational creativity (Boden 2009). This mental blending routinely takes place with no need of external, perceptual symbols-although perhaps never in a fully amodal way (Barsalou, Dutriaux, and Scheepers 2018)-but, in its basic and probably initial version, it does involve connecting a perceptual cue in the here-and-now with something else that is not present and is also usually unrelated (Mandler 2012; Mandler and Pagán Cánovas 2014).

Consider our ability to interpret inanimate secondary visual cues, that is, images or objects not directly associated with their referents (Mithen 1996: 203). Some primates have developed specialized alarm calls for different predators in the absence of any other relevant perceptual information. Although this behaviour may look imaginative, it is actually tied to a primary acoustic cue. Vervet monkeys, for example, have distinct vocalizations for eagles, leopards, and pythons (Cheney and Seyfarth 1988) but are unable to interpret that a python trail leading into a bush might indicate that the reptile is hidden there. In the absence of direct perception-smelling, hearing, or seeing the snake-vervet monkeys are unable to 'see' the track; to them, it is just a meaningless shape on the 
ground. On the contrary, human beings learn to integrate the trail and the snake it evokes into a track - a novel conceptualization unavailable from the snake or the trail in themselves - and, once they have interiorized it, cannot be prevented from evoking the virtual snake upon perception of the secondary visual cue (Pagán Cánovas and Turner 2016).

Besides its obvious advantages for survival, this capacity for anchoring the imaginarythe absent snake-on the present-the trail visible here and now-turns out to be crucial for grounding complex meanings on perceptions. This grounding allows us to reduce cognitive effort and to manipulate the form-meaning relation by acting directly on the material structure. Fictivity results from this anchoring: we notice the fictive snake and we imagine static objects using fictive motion-as denoted in sentences such as 'the road runs parallel to the coast' (Talmy 2003: 99-175). We can thus turn perceptual relations directly into conceptual relations by building material anchors, such as the clock that allows us to 'see' the time. This capacity is constantly employed in thought, communication, and action to facilitate mental blending, but it is important to understand that it is not symbolic in the same way as the words on this page, the notes on a stave or the signs in a cave painting. In symbols, form triggers meanings with no need of mirroring their structure. Thus different cues such as time, temps, or $\chi \rho$ óvoৎ can produce the same outcome. In anchors for blending, form is inseparable from meaning, since the whole material structure is projected into a mental space where the perceptual and the conceptual are fused (Hutchins 2005). This is what makes it impossible for us, once we have learned how to construct this blended space, not to see the hour on the clock, or the turns on a queue, or Europe and America on a map.

\subsection{Timelines}

The timeline is a very productive example of a material anchor for a conceptual blend. The blending pattern for spatialized time is a very complex one. It combines event structure, motion, mechanisms for measuring duration, and other inputs, which become integrated at different steps (Fauconnier and Turner 2008). Once a culture has developed a symbolic system such as the time-space blend, imaginative spatial time expressions flow effortlessly: time can fly or drag its feet depending on our feelings, or can halt when lovers look at each other in the eye.

However, there are still many things about temporality that are both important and hard to represent symbolically in a straightforward way, such as deixis along the past-presentfuture axis, diachrony, or complex sequences. By integrating different aspects of our spatial and temporal knowledge, timelines accomplish all these and more with great efficiency (Coulson and Pagán Cánovas 2013), thanks to our capacity for 'seeing' fictive motion along a path. As successful material anchors, timelines are very effective in compacting dispersed information into a single perceptual structure with multiple affordances: you can move along the timeline, zoom in and out, superimpose additional elements, and so forth. For instance, a linear chronography may split the periods of the history of music into segments in different colours, with dots marking masterpieces and parallel lines standing for the durations of composers' lives. Most people are so familiar with the timeline that they no longer need direct perceptual support, and regularly simulate interaction with an imaginary timeline in various cognitive tasks (Ulrich and Maienborn 2010; Weger and Pratt 2008). The same happens in face-to-face communication, combining language and gesture (Pagán Cánovas and Valenzuela 2017). Like any other material anchor, the timeline is a cultural creation with a considerable history of trial and error. Although at present it might seem an obvious representation that 
has always been available, the straight timeline was invented in the late eighteenth century (Rosenberg and Grafton 2010). The emergence of novel time representations in music has also required considerable struggle. It is precisely one of these moments of struggle that the sketches of our spectral composers reflect.

\section{TIMELINES IN SPECTRAL COMPOSITION}

\subsection{Blending staves and spectrograms}

Grisey's Périodes (1974) for seven musicians and Partiels (1975) for eighteen musicians are foundational works of the spectral movement. They are also paradigmatic examples of the conceptual integration of traditional staves and spectrograms via the timeline. Important notions of acoustics already informed the conception of musical time for Dérives (1973-4), for two orchestras (Féron 2011: 353-4), but there is no trace of spectrogram-like outlines in the sketches of this work, unlike what we find within the compositional traces Grisey has left for Périodes and Partiels. For these compositions, he was very likely to have only got general inspiration from unrelated, pre-existing spectrograms instead of computer analyses generated by himself. He once stated that the final measures of Périodes and the opening of Partiels, which are identical, originated from 'the analysis of the spectrum of a trombone on the same note [E]' (Grisey 1991: $356),{ }^{1}$ but his sketches for these pieces show no spectrogram or computer dataset (Féron 2010b: 437-41; also checked by us at Paul Sacher Stiftung). Only since orchestral pieces Modulations (1976-7) and Transitoires (1980-1) is it reasonable to suppose that Grisey had been able to generate such data, thanks to his collaboration with acoustician Michèle Castelengo during that period (Féron 2010b: 416). Grisey had had no access to actual tools for sonographic analyses before (438)-a fact that contradicts previous hypotheses (Baillet 2000: 14)-and he did not collaborate with institutions such as the IRCAM until the eighties. Nevertheless, at the time of Périodes and Partiels, he was already familiar with the spectrographic representations of sounds by authors such as Émile Leipp (Féron 2010a: §7).

The large synoptic sketch for the first section of Partiels (figure 1) matches a series of plateau-like shapes evoking spectrograms with the composer's actual strategies for instrumental synthesis. This compositional technique was, in his own words, nothing but 'the projection of the natural structure of sounds onto a dilated and artificial space' (Grisey 1991: 356). In more poetic words, he aimed at inducing 'the effect of a zoom lens,' which would lead to 'the very heart of sound whose material is revealed by the effect of an inordinate magnification' (Grisey 1987: 259). The sketch mentioned above is hybrid, both concerning the scriptural support and the types of information it provides. The upper half, written on squared paper, displays a sequence of eleven evolving plateaus; on them, durations are expressed through a timeline in which the lower side of each of the printed squares is equivalent to four semiquavers. The lower half of the sketch, written on music paper, provides information, for each of the plateaus above, about pitches standing for frequencies, their intensities, and some eventual extended techniques.

A spectrogram of the sort Grisey had seen offers a representation of sound along a twodimensional timeline, with the horizontal axis used for time and the vertical for sound frequency. It is a double material anchor, where durations and frequencies can be directly visualized, thus offering the possibility of simultaneous perception of the evolution of both magnitudes as the trained observer's gaze glides over the visualisation. It allows for

\footnotetext{
${ }^{1}$ All translations are ours.
} 
the connection of durations and frequencies across different moments at a glance, as well as for jumping ahead or backwards without being tied to a particular sequence. Conversely, stave notation is not a material anchor but a writing code that uses arbitrary conventions to represent pitch and rhythm in sequences of notes. By facilitating the division of sound into discrete units that can be 'read,' the stave is akin to alphabetic writing, which encodes speech articulations into letters. But both sound and speech are continuous phenomena, artificially broken into compositional measures by these Western cultural conventions.

Grisey's sketch reveals an evaluation of the useful insights that the new medium-boosted by the apparition of a new technology for anchoring acoustic properties- can offer for integration with the traditional writing system. The resulting score is a hybrid representation that recombines the properties of the music writing code and those of the material anchor for acoustic visualization, creating opportunities of its own. This perspective is conceptually different from François-Bernard Mâche's, who antedated the spectral composers in the use of spectrograms with Le son d'une voix (1964) for instrumental ensemble. Mâche did not operate scrupulous algorithmic transcriptions but conceived, first and foremost, 'systems of writing equivalence' (Assayag and Bloch 1997: 142), revealing a mimetic attitude towards composition (O'Callaghan 2015: 235). Grisey had different goals and a different strategy. Instead of seeking equivalences between the two systems, he was struggling to incorporate ideas such as the sound zooming effect, in order to generate his own new musical experiences.

As we repeatedly see across all examples of conceptual integration, the blending process is always goal-oriented. In spatialized time, for example, there is a clear tendency to create a mental scene that suits the representational goals of temporality, thus preferring a linear disposition where all observers are located on the same spot and objects move along a straight path (Fauconnier and Turner 2008; Pagán Cánovas, Valenzuela, and Santiago 2015). Thus, Grisey's early knowledge of spectrograms was in all probability crucial for him to imagine zoom-in effect by means of an artificially dilated space. Moreover, its implementation would be facilitated by selecting some anchoring properties of the spectrogram and integrating them with the staves into a hybrid representation within the score, where useful emergent structure would arise. The baseline idea was that, since sound can be de-composed into frequencies thanks to the anchoring properties of the spectrogram, something analogous can be done with time. Consequently, Grisey split traditional parameters of musical composition into two parallel notations within the aforementioned sketch: one for time and one for pitch and intensity. Consistent with spectrographic representations, duration is represented as a linear extension in the temporal notation above, while the pitches and intensities below remain attached to the symbolic tradition of Western music, albeit deprived of rhythm.

Grisey's score captures this hybrid strategy. The opening of Partiels is written with traditional staves but incorporates measures divided into proportional grids as well as sustained pitches that are notated by lines, which brings to mind the trails of overtones in spectrograms, instead of the usual ties. As it is typical in the development of material anchors, the creative process undergoes trial and error along intermediate stages, in which we can witness network effects as the whole conceptual architecture is being built and adjusted. Grisey had already used horizontal lines prolonging noteheads before composing Périodes and Partiels, as happens for instance in the opening of Dérives, along its violin cadenza. Its notation is however approximative: the soloist is requested to intuitively adapt the different lengths of the segments to a whole predetermined duration. Later on, several passages of Périodes are less ambiguous: their rhythmic notation still remains quite loose, but little vertical landmarks over the musical bars, 
functioning like a timeline grid, narrow down ambiguity. This strategy brings into mind the representation of the electronic tapes in the scores of mixed music. Grisey's hybridization of the symbolic and the proportional time notations became, in any case, fully accomplished and systematised with Partiels.

\subsection{Rethinking unidimensionality}

Once a material anchor is incorporated into a conceptual integration network, new possibilities open for manipulating its perceptual properties, which automatically cause meaningful effects by projecting back inferences from the blend to the inputs. In the case of the timeline, we can zoom in or out by assigning different values to a segment. The chronographic timeline can represent, for instance, the life of a person, the geological periods of the earth, or the plot of a movie. We can also introduce additional dimensions, or modify the typically straight linear shape of the timeline. When meaning is materially anchored, each change in perceptual structure has a direct outcome in conceptual structure, because the material properties of the anchor are a constitutive element of the thinking process. Thus when the hands on a clock or the shadow on a sundial change position, the observer that has been trained to inhabit those representations will unavoidably 'see' a change in the time. A change in the anchor's perceptual properties can afford novel opportunities for building richer and more detailed conceptual blends. The evolution of time-measuring mechanisms can, for instance, have a great influence on how people think about time, with a clock or a modern chronometer affording more complex temporal thinking than a sundial.

As we see, the manipulations of the anchor and the blending network are quite often brought by technological evolution. For example, in Grisey's Partiels, the duration of each musical block matching with each plateau-like shape is ten seconds average. That is about four times the maximal length that a sound file could have for being transcribed as a spectrogram with the technological devices of the seventies (Féron 2010b: 438). This proportion is quite modest if compared with the much larger ones that arise in our following case studies, all of which benefit from the plasticity of the timeline.

Saariaho's electronic piece Vers le blanc (1982) was composed during her first stay at IRCAM, in which she got trained in computer music-for instance, in rescaling time of sound data (Saariaho 1985: 164)-and did some research on musical timbre (McAdams and Saariaho 1985). She described her tape as 'an extreme example of the use of slowness', based on 'a tightly-knit whole by relating form and content in a radical manner' (Saariaho 1987: 104). Two years after, she somehow transferred this conception into the context of mixed music with Verblendungen (1984) for chamber orchestra and tape. In her own words, she imagined 'an "impossible" overall form' that 'would begin at its highest point and whose infolding would be merely a winding down after the initial burst of energy' (Saariaho 1987: 107).

An image from visual arts, a discipline Saariaho studied when she was young, helped her to formally conceptualize the piece (figure 2, first published in Saariaho 1987, reprinted in Pousset 1994; 2000). The brushstrokes are similar, visually speaking, to 2D spectrograms but also capture the idea of a one-stroke gesture. However, no 2D spectrograms are to be found among the sketches for Verblendungen at Paul Sacher Stiftung. Instead, we have formant envelopes and waterfall plots, that is, 3D spectrograms, which show substantial overlap (figure 3). Our hypothesis is that Saariaho mentally matched the brushstrokes with spectrograms but, instead of mapping the ink trail of any bristle with the intensity of any frequency in plane sonograms, waterfall plots helped her to conceptualize otherwise. Three-dimensional spectrograms display 
intensities as polygonal variations over time for each frequency, and this is precisely how Saariaho developed her formal conception of the piece. Indeed, she conceived polygonal graphs within a bidimensional space, wherein the horizontal axis was always time whereas the vertical one stood, in each case, for pitch, register, dynamics, polyphonic activity, balance with the tape, and so forth. (Saariaho 1987: 107). By using transparencies to superpose all her curves-that is, simulating again three-dimensionalityshe was thus able 'to conceive the whole work second by second.' (108)

In this way, Saariaho was exploiting one of the major functions of blending: turning what would otherwise be diffuse and scattered in the mind into a human-scale, manageable representation. Recurrent acts of blending seeking to achieve an appropriate mental scale have the effect to create entrenched patterns for compression. In blending, compression transforms relations between separate mental spaces into one single relation in the blend (Fauconnier 2005). Consider a sentence such as 'my electricity bill keeps growing every month'. We know that this does not mean that the paper where my bill is written actually gets bigger. We also know that there is one single bill, but that every month a new one arrives. We can think of each of these bills separately, in an individual mental space: the January bill, the February bill, and so forth. We can also establish an analogy connection across all these mental spaces: they are almost identical, except for some disanalogies, that is, properties of the bills where the otherwise-complete analogy stops, ${ }^{2}$ allowing for variation in specific values, in this case the date, the reference number, or the amount due. As they stand now, with disperse information, it is hard to establish a meaningful relation between multiple monthly bills. But our minds have learned a routine that can help. To make the conceptual network less diffuse, we can integrate separate mental spaces in the right way. In cases like this, practice has taught the mind to fuse all the analogous mental spaces into one entity: this compresses the analogy relation between the monthly bills into one of identity. Then we can also compress the most relevant disanalogy across the monthly bills, that is, the different amounts due for each bill, into change. Therefore, that change can now be situated within the single entity where they have all been fused, the one electricity bill in the blend. The result is that now the monthly bills with different amounts due have become a single bill that grows. The idea of an entity that changes by growing is unavailable anywhere outside the blend: it is not in the January bill, or in the February one, or in any other input.

Human beings routinely reason by compressing relevant relations such as analogy or disanalogy into different relations in the blend, such as identity or change. Thus we can come up with a growing electricity bill, a decreasing deficit figure, days that get longer in summer and shorter in winter, and innumerable other representations. To make sense of these compressions, de-compressing the blend is equally important. In this case, to make sense of 'my electricity bill keeps growing every month', we need to be able to unpack the single electricity bill into the multiple monthly bills that have been fused into it. In other words, we need to make the connections between analogy-disanalogy and the tandem identity and change that hold across the mental network. This same standard procedure of conceptual integration is at work in Saariaho's composition. The simulation of waterfall plots via transparencies compressed the unfolding of various magnitudes in the piece, allowing her to plan the overall structure of the composition accordingly. The shared timeline for each magnitude stabilises the compression. Just as in the electricity bill example, the blend makes sense only if it can be de-compressed into its inputs: the comparative measures of various magnitudes involved in the composition process.

\footnotetext{
${ }^{2}$ Disanalogy is the term that cognitive linguists use for highlighting relevant differences among inputs of a conceptual blending (Turner 2007).
} 
Verblendungen stands as a good example of Saariaho's implementation of the sound/noise axis that she conceived in the eighties (Saariaho 1987: 94-7). A few years before, Grisey had a relatively similar idea when he conceived the notion of sound shadows. In his own words, around each complex sound there would be 'an aura of sum and difference tones' and, consequently, 'sounds have a shadow' (Grisey 1991: 369): intervals based on the harmonic series would have no shadows whereas the other intervals would generate complex combination tones. This dichotomy is at the basis of Sortie vers la lumière du jour (1978), a piece for electric organ and ensemble he reworked for including a tape, thereby giving rise to Jour, Contre-jour (1978). Both versions are structured as a so-called 'process of successive phases' in which the 'sound archetype' and the 'noise archetype' alternate (Baillet 2000: 157-9).

Evidence of cross-modal correlation between perceived musical pitch and light brightness (Marks 1989) may explain the perceptual background of Grisey's conception of his sound shadows. In particular, the pitches of Jour, Contre-jour overall move from the treble register to the bass one while the duration of the sound archetypes wanes for giving more and more room to noisy ones (Baillet 2000: 161). More important for our topic, this crossmodality also entails temporal consequences. Among Grisey's sketches for Sortie vers la lumière du jour, there is a timeline representing the 24 hours of a day (figure 4). This timeline displays pitch information by unfolding it as a curtain in relation with time, just as we see in many chronographies that need to include, for example, explanations of individual events alongside their historical sequence. Thus Grisey's sketch distributes a set of descriptive elements depending on the daily luminosity. For instance, noon corresponds to 'spectral luminosity,' midnight to 'white noise', and sum tones are identified with 'sound light,' while difference tones are identified with 'sound shadows.' Adding yet another dimension, the large arrows arising from the timeline and descending back-for an emphasis of the unfolding data over the timeline-make the schema, geometrically speaking, akin to the spectrogram-like shapes we found in Grisey's previous sketches.

\subsection{Spiral timeline}

This section and the next one focus on two case studies in which curvy representations of time are found in compositional sketches. Although this choice seems to be in conflict with any temporal conceptualization based on spectrograms, productive compositional strategies are built on the clash between the two structures. Spectrograms and, in a broader sense, the composers' experience in electroacoustic studios, stood as crucial bridges for transferring cognitive structure from non-straight timelines into the scores.

The aforementioned notion and process of successive phases has been compared by researchers on spectral music with the anamorphosis in visual arts. The underlying idea is to 'develop into a rich reservoir of musical and formal material that can sound very different in spite of its high degree of relatedness, creating very different and surprising effects without compromising the coherence of the musical material' (Fineberg 2000: 109). This analogy with painting is picked up again for explaining some cyclic aspects of Saariaho's string quartet with live electronics Nymphéa (Rofe 2011: 88-93), providing also a kind of helicoidal-blossom-schema which summarizes its musical form (98). The choice of a flower is consistent with Saariaho's source of inspiration-Monet's series of Water Lilies-and the disparate size of its petals somehow captures the anamorphic idea. Michael Rofe's intuition is particularly striking because he was probably unaware-as he does not mention it-that, among Saariaho's sketches for the string quartet, there are two spiral timelines. The first one (figure 5) splits the total timing that she had at first 
conceived for her piece, and which is noticeably shorter than the final result, into consecutively larger segments. The second timeline, polygonal and apparently related to a particular section (figure 6), uses four colours matching with each possible directionsides up, down, left, and right-and provides a set of expressions alluding to instrumental techniques or musical qualities.

We have not found a scrupulous correspondence of Saariaho's spiral timelines with her score. Nevertheless, two salient aspects seem to be nested within the final outcome: discontinuous equivalences and time expansions. Some passages of Nymphéa are indeed dilated versions of non-contiguous and shorter passages that were heard before. Rofe provides an example of expansion based on the repetition of pitch fields, but other situations are reported (figure 7): for instance, a very short homorhythmic transition between sections (b. 39) is further remade as two synchronised waves with a harmonic enlargement (bb. 196 and 199). Both the example pointed out by Rofe and ours share two musical features when the passage is dilated: the prolonged use of bow overpressure on the strings and a sharper use of the live electronic treatments. Their combination emphasises, aurally speaking, a subjective perception of time dilatation by enriching the spectral qualities of the instrumental sound and using its spatial projection in the concert hall. Saariaho's expanded reprises are therefore in tune with Grisey's idea of zoom into the sound.

These features in the music reflect a manipulation of the material anchor. By virtue of decompression, any manipulation of perceptual properties in the blend must directly project an inference on one or more of the input mental spaces, or on the relations between them. The inferences projected back to the inputs tend to be structurally different from the manipulation in the blend that triggered them. In particular, when such de-compressions are triggered by direct perception, as happens with material anchors, the organization of the meaning is greatly facilitated. Compare a detailed examination of the monthly electricity costs in the 'electricity bill' blend we provided above with a cartoon where a monstruous electricity bill keeps growing until it explodes. The second representation helps us organize the relations between the bills in a much more straightforward manner. We find an analogous procedure in the Nymphéa sketch. The spiral line anchoring Saariaho's time representation cannot be mirrored in the composition, because there is in fact no spiral shape in music notation. But the perceptual structure of the spiral anchor is meant to inspire a corresponding musical structure. Indeed, the structure of the composition is modulated so that it presents features that are congruent with some of the generic structure of a spiral, in this case, recurrences of previous sound sequences, that re-appear in a reshaped but recognizable fashion. A straight line, meant to enhance evolution and continuity, would be useful for other modulations, but not for such a cyclic organization. By spiralling the timeline, Saariaho was able to more easily find that effect of modified recurrence, which in turn creates a particular sense of temporality in the piece.

\subsection{Springy timeline}

Grisey once borrowed the expression 'arrow of time' from astronomy and thermodynamics for better explaining his processual conception of music (Grisey 1987: 249). His scientific interests were particularly evident while composing Le Noir de l'Étoile (1989-90) for six percussionists, electronics, and live astronomic signals, with some theoretical feedback brought by astrophysicist Jean-Pierre Luminet. During this collaborative period, they discussed many physical cutting-edge topics, among them John Wheeler's quantum foam (Luminet 2011: 422-3). The suggestive image of tiny 
fluctuations within the spacetime inspired the title of Le Temps et l'écume (1988-9) for four percussionists, two synthesisers, and chamber orchestra.

Did quantum mechanics have an impact on Grisey's compositional practices? As shown by previous analyses, this piece is articulated in three sections, matching with three categories of time that the composer started to elaborate in the eighties, namely the 'time of humans', 'the time of birds'-alternatively insects-and the 'time of whales' (Baillet 2000: 185-98). Although these categories have nothing to do with quantum mechanics, we have found a sketch at Paul Sacher Stiftung that maybe points in this direction, since its springy shape deliberately violates the ineluctable arrow of time (figure 8).

Below the springy timeline in his sketch, Grisey wrote 'rotation around formant 56 or pendulum'. This clue helps to track down its corresponding passage within Le Temps et l'écume, spanning from rehearsal number 16 to 20. The passage belongs to the first section of the piece that unfolds slow concatenation of spectral-based harmonies in which their fundamentals describe a descending path (Baillet 2000: 187). Two instrumental blocks are opposed: winds on the one hand; strings, percussion, and synthesisers on the other hand. A schematic reduction of the aforementioned passage (figure 9) sheds light on Grisey's compositional strategies. First, the synthesisers and the brass section share, if we ignore the octave transposition, the same pitch materials. Second, the harmonic blocks are not juxtaposed but overlap. A subtle fadeout of the electronic sounds operates a smooth merger of both features, which are thus consistent with the springy timeline in a way analogous to Saariaho's spiral timeline. Modifying the perceptual shape of the timeline through the sketch directly modifies the conceptualization of time in the piece via compression and de-compression, and this is reflected in the patterning of the composition, in this case, similar music materials across overlapping events.

Both similarity and overlap have been for centuries the bases of imitative counterpoint in Western music. Within this context, the French composer's notion of 'spectral polyphony' emerged as a way to organise musical layers that are 'differentiated enough, but come from a common field of organization' (Grisey 1991: 384). Such a common field can be a formantic region, as hinted for instance in a compositional sketch Grisey did for Le Temps et l'écume (figure 10). His draft displays overlapping spectrogram-like shapes but highly deformed, as if they were waves under the action of strong tidal forces. This kind of inertial strains are not strictly captured within the score, but our schematic reduction shows, for instance, how a passage of the woodwinds unfolds like an inverted plateau, visually speaking. The spectrographic analyses of acoustic instruments do not generally provide outcomes with this visual shape; instead, electroacoustic techniques easily allow us to synthesise sounds matching with it. Consequently, Grisey's experience in electronic studios probably helped him to conceptually operate this manipulation.

\section{DID YOU SAY SPECTRAL? FUTURE DIRECTIONS AND SYNERGIES}

The fundamental cognitive capacities for blending and anchoring were indispensable to build the conceptions of time at work in Grisey's and Saariaho's compositional practices. Unlike a mere imitation or transcription, the really productive approach results from Grisey's integration of selected elements from the timeline structure of the spectrogram with the stave notation. We routinely see this process of reblending and overlap across multiple generic patterns for conceptual integration (Turner 2014). Besides selective projection of various features, the lesson we learn from Grisey is that the general insights derived from a mental space or blending network can be incorporated into another blend to create new structure. Just as Picasso incorporated general know-how from traditional African mask design to create cubism in the Demoiselles d'Avignon, Grisey brought the 
gist of spectrographic sound representations to his notational blend, leading to new conceptions of musical time. Once he achieved this blend, the conceptual network could be apprehended by other composers, discovering further creative possibilities such as the later manipulations that we have analysed, by Saariaho and by Grisey himself.

We have highlighted twice how the emergence of blends and anchoring processes runs in parallel with the technological developments of a culture. Concerning our topic, we have provided several examples of the essential impact of computer data and the use of electroacoustic techniques in Grisey's and Saariaho's conceptualizations of time. Those creative conceptions could not have been developed outside their technological context. The process is not unidirectional, from technological anchor to artistic outcome, but an interactive one, a back and forth movement connecting the electroacoustic lab and the composer's desk. This feedback loop, fuelled by non-musical inputs-Saariaho's attention to Monet's Water Lilies, Grisey's interest in quantum physics-challenges Grisey's famous claim pointing towards sound as the only legitimate model for composers (Grisey 1982: 22). Coherently with the multimodal, perceptually-grounded dynamicity of human cognition (Barsalou 2008), music does not inhabit a mental sphere that is fully detached from other domains.

Analyses such as the ones proposed here are steps in two productive directions. One is, indeed, the study of compositional practices using theoretical frameworks from the cognitive sciences. Here we had no room to introduce more complex notions explaining conceptual blends and anchoring processes, but we have shown that important insights can be reached by studying the basic cognitive operations at work in composition. For example, we have offered a scientific argument for explaining Grisey's first spectral compositions as resulting from generic knowledge of spectrograms, rather than from specific spectrographic representations. We have also put forward a comparative method to reach a better understanding of the structural connections between different works by Saariaho and Grisey.

Besides all these possibilities, the second direction shows even more attractive prospects. Studying musical phenomena with methods and theoretical frameworks shared with the cognitive sciences allows musicologists to directly engage in the general conversation about creativity and cognition. As they accumulate more cases and further details, methods such as the ones proposed here can have an impact on theories about how the mind works, especially about how creative and representational processes unfold, evolve in cultural diachrony, and feed one another. Glimpses offered here include the idea of projecting evaluations or general know-how from one blend to another, the diachronic struggle to develop material anchors and representational goals in a feedback loop, or the use of basic operations in spatial cognition to manipulate conceptual structure. All these are topics of great interest to the cognitive sciences, from linguistics to psychology and AI; these research fields require much more data and comparative analyses if we are to attain far-reaching insights. Music, in a broad sense, already plays a major role in this enterprise, but there is also a special potential for current musicology. Since it has the advantage of a richer and more direct access to invaluable multimodal data related to recent compositional practices, it can offer invaluable contributions to the study of time concepts in general, abstract representations, and creativity.

\section{REFERENCES}

Assayag, G., and Bloch G. 1997. Quantification et création musicale. In M. Grabócz (ed.) Les modèles dans l'art: Musique, peinture, cinéma. Strasbourg: Presses Universitaires de Strasbourg, 127-55. 
Baillet, J. 2000. Gérard Grisey: Fondements d'une écriture. Paris: L'Itinéraire/L'Harmattan.

Barsalou, L. W. 2008. Grounded Cognition. Annual Review of Psychology 59 (1): 61745.

Barsalou, L. W., Dutriaux, L., Scheepers, C. 2018. Moving Beyond the Distinction between Concrete and Abstract Concepts. Philosophical Transactions B 37: 20170144.

Besada, J. L. 2019a. Different Trails: On the Multiple Genetic Roots Determining a Distributed Compositional Project. Tempo 73(290): 56-72.

Besada, J. L. 2019b. Where Science-Based Music Comes From: Some Cognitive Remarks upon Contemporary Compositional Practices Inspired by Mathematical Concepts, Operations, and Objects. In R. Illiano (ed.) Twentieth-Century Music and Mathematics. Turnhout: Brepols, 261-77.

Boden, M. A. 2009. Computer Models of Creativity. AI Magazine 30: 23-34.

Cheney, D., and Seyfarth, R. 1988. Assessment of Meaning and the Detection of Unreliable Signal by Vervet Monkeys. Animal Behaviour 36: 477-86.

Coulson, S., and Pagán Cánovas, C. 2013. Understanding Timelines. Journal of Cognitive Semiotics 5(1-2): 198-219.

Deacon, T. W. 1998. The Symbolic Species: The Co-evolution of Language and the Brain. New York: W. W. Norton \& Company.

Dufourt, H. 2004. Gérard Grisey: La fonction constituante du temps. Musicace Scientiace 8(1 suppl): 47-69.

Exarchos, D. 2018. The Skin of Spectral Time in Grisey's Le Noir de l'Étoile. TwentiethCentury Music 15(1): 31-55.

Fauconnier, G. 2005. Compression and Emergent Structure. Language and Linguistics 6(4): 523-38.

Fauconnier, G., and Turner, M. 2002. The Way We Think: Conceptual Blending and the Mind's Hidden Complexities. New York: Basic Books.

Fauconnier, G., and Turner, M. 2008. Rethinking Metaphor. In R. W. Gibbs (ed.) The Cambridge Handbook of Metaphor and Thought. Cambridge: Cambridge University Press, 57-66.

Féron, F.-X. 2010a. Gérard Grisey: première section de Partiels (1975). Genesis 31: 7797.

Féron, F.-X. 2010b. Sur les traces de la musique spectrale: Analyse génétique des modèles compositionnels dans Périodes (1974) de Gérard Grisey. Revue de Musicologie 96(2): 411-43.

Féron, F.-X. 2011. The Emergence of Spectra in Gerard Grisey's Compositional Process: From Dérives (1973-74) to Les espaces acoustiques (1974-85). Contemporary Music Review 20(5): 343-75.

Fineberg, J. 2000. Guide to the Basic Concepts and Techniques of Spectral Music. Contemporary Music Review 19(3): 81-113.

Grisey, G. 1982. La musique: le devenir des sons. Darmstädter Beitrage zur Neuen Musik 19: 16-23.

Grisey, G. 1987. Tempus ex Machina: A Composer's Reflections on Musical Time. Contemporary Music Review 2(1): 239-275.

Grisey, G. 1991. Structuration des timbres dans la musique instrumentale. In J.-B. Barrière (ed.) Le timbre, métaphore pour la composition. Paris: Christian Bourgois/Ircam-Centre Pompidou, 352-85.

Grisey, G. 2000. Did You Say Spectral? Contemporary Music Review 19(3): 1-3. 
Hall, P., and Sallis, F. (eds.). 2004. A Handbook to Twentieth-Century Musical Sketches. Cambridge: Cambridge University Press.

Hutchins, E. 2005. Material Anchors for Conceptual Blends. Journal of Pragmatics 37: $1555-77$.

Kendall, G. 2010. Meaning in Electroacoustic Music and the Everyday Mind. Organised Sound 15(1): 63-74.

Koestler, A. 1964. The Act of Creation. New York: Macmillan.

Luminet, J.-P. 2011. Illuminations: Cosmos et esthétique. Paris: Odile Jacob.

Mandler, J. M. 2012. On the Spatial Foundations of the Conceptual System and Its Enrichment. Cognitive Science 36(3): 421-51.

Mandler, J. M., and Pagán Cánovas, C. 2014. On Defining Image Schemas. Language and Cognition 6(4): 510-32.

Manfrin, L., and Piras, M. 2003. Spettromorfologia, durata e differenza: La presenza di Bergson nel pensiero musicale di Gérard Grisey. Rivista Italiana di Musicologia 38(1): 75-117.

Marks, L. E. 1989 On Cross-modal Similarity: The Perceptual Structure of Pitch, Loudness, and Brightness. Journal of Experimental Psychology: Human Perception and Performance 15(3): 586-602.

McAdams, S., and Saariaho, K. 1985. Quality and Functions of Musical Timbre. Proceedings of the 1984 International Computer Music Conference. San Francisco: ICMA, 367-74.

Mithen, S., 1996. The Origin of Art: Natural Signs, Mental Modularity, and Visual Symbolism. In H. D. M. Maschner (ed.) Darwinian Archaeologies. New York: Springer, 197-217.

Mithen, S. 1999. The Prehistory of the Mind: The Cognitive Origins of Art, Religion and Science. London: Thames \& Hudson.

O'Callaghan, J. 2015. Mimetic Instrumental Synthesis. Organised Sound 20(2): 231-40.

Orcalli, A. 1991. Gérard Grisey, 'durée réelle' e dilatazione del tempo musicale. Sonus 3(4): 38-68.

Pagán Cánovas, C., and Turner, M. 2016. Generic Integration Templates for Fictive Communication. In E. Pascual and S. Sandler (eds.) The Conversation Frame: Forms and Functions of Fictive Interaction. Amsterdam: John Benjamins, Amsterdam, 45-62.

Pagán Cánovas, C., Valenzuela, J., and Santiago, J. 2015. Like the Machete the Snake: Integration of Topic and Vehicle in Poetry Comprehension Reveals Meaning Construction Processes. Psychology of Aesthetics, Creativity, and the Arts 9, 38593.

Pagán Cánovas, C., and Valenzuela, J. 2017. Timelines and Multimodal Constructions: Facing New Challenges. Linguistics Vanguard 3(s1): 20160087.

Pasler, J. 2004. Resituating the Spectral Revolution: French Antecedents and the Dialectic of Discontinuity and Continuity in Debussy's Jeux. Musicace Scientiace 8(1_suppl): 125-40.

Pousset, D. 1994. La transparence du signe. In R. Nieminen (ed.) Kaija Saariaho (Les cahiers de l'Ircam 6). Paris: Ircam-Centre Pompidou, 25-42.

Pousset, D. 2000. The Works of Kaija Saariaho, Philippe Hurel, and Marc-André Dalbavie-Stile Concertato, Stile Concitato, Stile Rappresentativo. Contemporary Music Review 19(3): 67-110.

Rofe, M. 2011. Capturing Time and Giving it Form: Nymphéa. In T. Howell, J. Hargreaves, and M. Rofe (eds.) Kaija Saariaho: Visions, Narratives, Dialogues. Abingdon/New York: Ashgate, 81-105. 
Rosenberg, D., and Grafton, A. 2010. Cartographies of Time: A History of the Timeline. New York: Princeton Architectural Press.

Saariaho, K. 1985. Shaping a Compositional Network with Computer. Proceedings of the 1984 International Computer Music Conference. San Francisco: ICMA, 163-5.

Saariaho, K. 1987. Timbre and Harmony. Interpolation of Timbral Structures. Contemporary Music Review 2(1): 93-113.

Saariaho, K. 2000. Matter and Mind in Music. In P. Tuukkanen et al. (ed.) Matter and Mind in Architecture. Helsinki: Alvar Aalto Foundation, 110-15.

Sijouva-Gunaratman, A. 2003. Miniatures and Tensions: Phenomenological Reverberations in and around Kaija Saariaho's Lichtbogen (1985-86). Intersections 25(1-2): 44-66.

Talmy, L. 2003. Toward a Cognitive Semantics, Volume 1: Concept Structuring Systems. Cambridge, MA: The MIT Press.

Turner, M. 2007. Conceptual Integration. In D. Geeraerts, and Hubert Cuyckens (eds.), The Oxford Handbook of Cognitive Linguistics. Oxford/New York: Oxford University Press, 377-93.

Turner, M. 2014. The Origin of Ideas: Blending, Creativity, and the Human Spark. New York: Oxford University Press.

Ulrich, R., and Maienborn, C. 2010. Left-right Coding of Past and Future in Language: The Mental Timeline During Sentence Processing. Cognition 117, 126-38.

Weger, U. W., and Pratt, J. 2008. Time Flies Like an Arrow: Space-time Compatibility Effects Suggest the Use of a Mental Timeline. Psychonomic Bulletin and Review $15,426-30$.

Zbikowski, L. 2019. Cognitive Extension and Musical Consciousness. In R. Herbert, D. Clarke, and E. Clarke (ed.) Music and Consciousness 2: Worlds, Practices, Modalities. Oxford: Oxford University Press, 34-54. 